\title{
Intoxicação espontânea por Pterodon emarginatus (Fabaceae) em bovinos no Estado de Goiás ${ }^{1}$
}

\author{
Fabiano J.F. de Sant'Ana ${ }^{2 *}$, José N. Perin ${ }^{3}$, Ubirajara O. Bilego ${ }^{3}$, Rogério E. Rabelo ${ }^{4}$, \\ Valcinir A.S. Vulcani ${ }^{5}$ e Eric M.N. de Paula ${ }^{6}$
}

\begin{abstract}
Sant'Ana F.J.F., Perin J.N., Bilego U.O., Rabelo R.E., Vulcani V.A.S. \& Paula E.M.N. 2012. [Spontaneous poisoning of cattle by Pterodon emarginatus (Fabaceae) in Goiás, Brazil.] Intoxicação espontânea por Pterodon emarginatus (Fabaceae) em bovinos no Estado de Goiás. Pesquisa Veterinária Brasileira 32(6):485-489. Laboratório de Patologia Veterinária, Campus Jataí, Universidade Federal de Goiás, Jataí, GO 75801-458, Brazil. E-mail: santanafjf@yahoo.com

An outbreak of poisoning by Pterodon emarginatus in cattle in Goiás, Brazil, is described. Eighty four cattle that accidentally consumed the leaves and fruits from a P. emarginatus tree, fallen in a storm, were affected and seven died. Clinical signs included piloerection, flank retraction, marked apathy, prostration, muscle tremors, muzzle dryness, tenesmus, incoordination, reluctance to move, and prolonged sternal recumbency. AST, ALT, and GGT serum activity, and bilirubin levels were markedly increased. Gross lesions included hepatomegaly, multifocal areas of necrosis in the liver, and hemorrhages in the heart, parietal pleura, mesentery, omentum, ruminal serosa, spleen, lung, subcutaneous tissue, and thoracic and intercostal skeletal muscles. Histologically, moderate to severe, massive hepatocellular degeneration and necrosis with moderate bile duct hyperplasia and mild bile stasis were observed. In addition, moderate multifocal vacuolar degeneration in the convoluted renal tubular cells was noted.
\end{abstract}

INDEX TERMS: Poisonous plants, Pterodon emarginatus, Fabaceae, plant poisoning, cattle.

RESUMO.- Descreve-se um surto de intoxicação por Pterodon emarginatus em bovinos no Estado de Goiás. De um lote de 84 bovinos que comeram avidamente folhas e os frutos da planta após a queda acidental de uma árvore, todos os animais adoeceram e sete morreram. Os sinais clínicos observados foram eriçamento dos pelos, retração do flanco, apatia profunda, prostração, tremores musculares, ressecamento do focinho, tenesmo, incoordenação, relutância

\footnotetext{
${ }^{1}$ Recebido em 19 de novembro de 2011.

Aceito para publicação em 30 de dezembro de 2011.

${ }^{2}$ Laboratório de Patologia Veterinária (LPV), Universidade Federal de Goiás (UFG), Campus Jataí (CAJ), BR 364 Km 192, Jataí, GO 75801-458, Brasil.*Autor para correspondência: santanafjf@yahoo.com

${ }^{3}$ Cooperativa Agroindustrial dos Produtores Rurais do Sudoeste Goiano (Comigo), Av. São Roque s/n, Bairro São Simão, Indiara, G0 75955-000, Brasil.

${ }^{4}$ Setor de Cirurgia de Grandes Animais, Universidade Federal de Goiás, Campus Jataí, BR 364 Km 192, Jataí, GO.

${ }^{5}$ Laboratório de Anatomia, CAJ-UFG, Jataí, GO.

${ }^{6}$ Acadêmico de Medicina Veterinária, LPV/CAJ-UFG, Jataí, GO. Bolsista Probec/UFG.
}

em movimentar-se e decúbito esternal prolongado. As atividades séricas de AST, ALT e GGT e os teores de bilirrubina estavam acentuadamente elevados. As principais alterações macroscópicas consistiam de hepatomegalia e áreas multifocais de necrose no fígado, além de hemorragias no coração, pleura parietal, mesentério, omento, serosa do rúmen, baço, pulmão, subcutâneo e musculatura esquelética intercostal e torácica. Microscopicamente, observou-se degeneração e necrose hepatocelular massiva moderada a acentuada, hiperplasia biliar multifocal moderada e bilestase multifocal leve. Adicionalmente, notou-se degeneração vacuolar multifocal moderada nos túbulos contorcidos dos rins.

TERMOS DE INDEXAÇÃO: Plantas tóxicas, Pterodon emarginatus, Fabaceae, sucupira, sucupira-branca, faveira, intoxicação por plantas, bovinos.

\section{INTRODUÇÃO}

Pterodon emarginatus Vogel (sin. Pterodon pubescens Benth.) é uma espécie arbórea, aromática, nativa do cerrado brasileiro e de sua transição para a floresta semidecídua, 
encontrada nos Estados de Goiás, Mato Grosso do Sul, Minas Gerais e São Paulo, podendo atingir 8-16m de altura (Oliveira \& Paiva 2005, Lorenzi 2008). P. emarginatus pertence à família Fabaceae (= Leguminosae), subfamília Faboideae, e é conhecida popularmente como "sucupira", "sucupira-branca" ou "faveira". As sementes dessa planta são amplamente utilizadas com fins medicinais em função de suas ações antirreumáticas (Coelho et al. 2004), analgésicas (Coelho et al. 2005), antimicrobiana (Santos et al. 2010), anticercária (Mahajan \& Monteiro 1970), anti-inflamatória (Mors et al. 1967) e no tratamento de faringites, amidalites e bronquites em humanos. Outra importante utilidade da espécie é na indústria madeireira (Lorenzi 2008). A planta floresce entre setembro e outubro e a maturação de seus frutos ocorre em junho e julho (Lorenzi 2008).

Quadros de intoxicação em bovinos por folhas de $P$. emarginatus são raros e, recentemente, um surto foi descrito no Estado de Mato Grosso. Nesse episódio, quatro bovinos morreram de um lote de 80 vacas que consumiram as folhas da planta após a derrubada de duas árvores para aproveitamento da madeira. Os principais sinais clínicos observados foram de caráter neurológico e as lesões foram mais acentuadas no fígado, que consistiam essencialmente de necrose hepatocelular massiva. Nesse surto, a toxidez da planta foi comprovada pela reprodução da intoxicação em um ovino que apresentou quadro clínico e patológico muito semelhante ao visualizado nos bovinos (Arruda et al. 2008).

0 presente trabalho tem por objetivo descrever, pela primeira vez no Estado de Goiás, as características epidemiológicas, clínicas e patológicas de um surto de intoxicação espontânea por P. emarginatus em bovinos.

\section{MATERIAL E MÉTODOS}

O surto ocorreu no início de outubro de 2011 em uma propriedade rural de criação extensiva de bovinos Nelore PO no município de Indiara, região central de Goiás (latitude -17ํ0' 17', longitude -49-59'17', altitude 550m). Cinco bovinos doentes foram avaliados clinicamente. Após exame físico geral e prévia identificação, foi realizada coleta de sangue periférico para realização de bioquímica sérica (AST, ALT, GGT e bilirrubinas total, indireta e direta). 0 histórico clínico e epidemiológico foi obtido com o proprietário e o médico veterinário responsável pelo atendimento inicial. Dois bovinos (Bov.1 e 2) que morreram naturalmente foram necropsiados, onde foram coletados fragmentos de vários órgãos, os quais foram fixados em formol tamponado a $10 \%$, processados rotineiramente para histopatologia e corados por hematoxilina-eosina (HE).

\section{RESULTADOS}

0 proprietário havia colocado um lote de 84 bovinos (40 vacas [3-12 anos], 40 bezerros [8-12 meses] e quatro rufiões [3 anos]) em um piquete de Brachiaria brizantha com livre acesso a sal mineral e água de córrego de boa qualidade. A quantidade e qualidade da forragem nesse piquete eram insatisfatórias, pois o período chuvoso havia começado na região, há apenas oito dias, e ainda não havia boa disponibilidade de volumoso para o lote. 0 pouco capim disponível era muito seco. Após uma tempestade, com acentuada precipitação pluviométrica e fortes rajadas de vento, uma árvore de Pterodon emarginatus de aproximadamente $10 \mathrm{~m}$ caiu ao solo (Fig.1). Em seguida, todos os bovinos do lote comeram avidamente as folhas e os frutos da planta (Fig.2) que estavam a sua disposição, restando apenas às folhas das partes mais altas da árvore, onde os mesmos não alcançavam (Fig.1).

Três dias após a queda da árvore, todos os bovinos do lote manifestaram sinais de intoxicação e sete morreram (cinco vacas e dois rufiões) (morbidade 100\%, mortalidade e letalidade 8,33\%). Os sinais clínicos incluíam eriçamento dos pelos, retração do flanco, apatia profunda, prostração, tremores musculares, ressecamento do focinho, tenesmo, incoordenação, relutância em movimentar-se e decúbito esternal prolongado. Alguns bovinos apresentaram urina alaranjada com odor muito forte e outros permaneciam em decúbito lateral com a cabeça voltada para o flanco (Fig.3). Muitos animais pararam de ruminar, com ausência de movimentos ruminais completos em um período de cinco minutos. 0 curso clínico foi de 36-72 h. As atividades séricas de AST, ALT e GGT e os teores de bilirrubina total, direta e indireta estavam acentuadamente elevados nos bovinos avaliados do lote (Quadro 1).

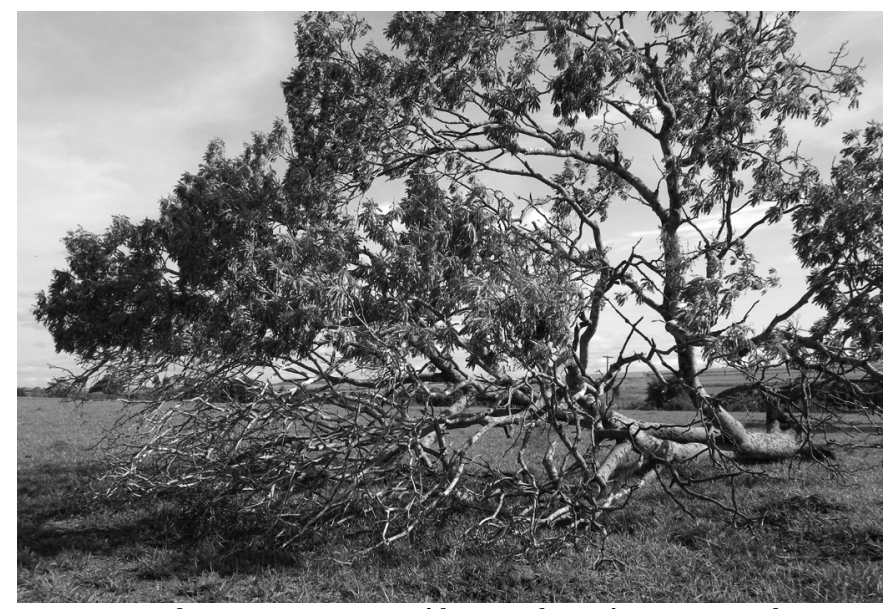

Fig.1. Pterodon emarginatus caída ao solo após tempestade. Nota-se que as folhas da árvore que ficaram ao alcance dos bovinos foram todas consumidas. Indiara/GO.

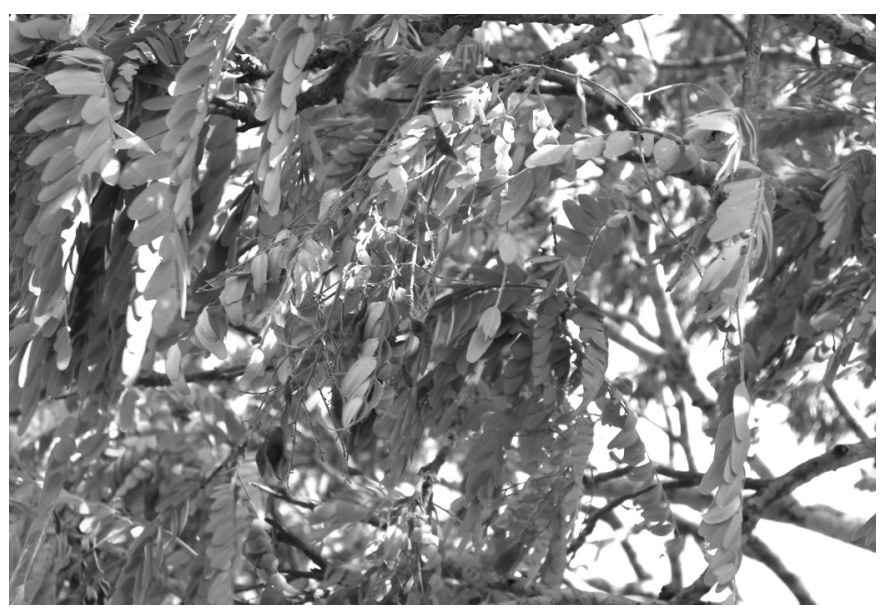

Fig.2. Detalhe das folhas e dos frutos maduros de Pterodon emarginatus. Indiara/GO. 


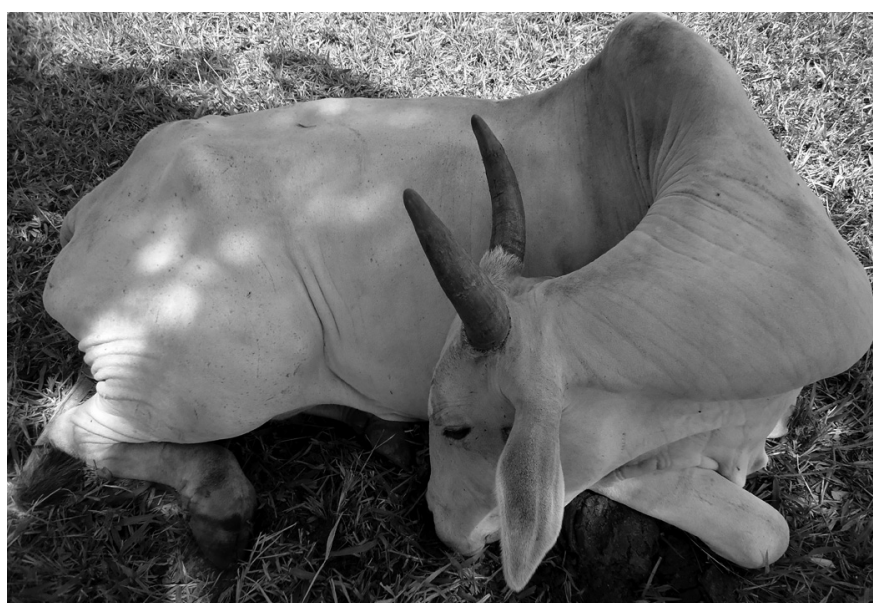

Fig.3. Bovino em decúbito esternal, extremamente prostrado e com a cabeça voltada para o flanco direito, na intoxicação por Pterodon emarginatus.

Macroscopicamente, foram observados, à necropsia, fígado aumentado de volume e com numerosas áreas irregulares, esbranquiçadas ou amareladas, friáveis, multifocais a coalescentes (Fig.4). A lobulação hepática era bastante evidente, principalmente após a fixação com formol (Fig.4). A vesícula biliar estava muito distendida e com parede edemaciada. Petéquias e equimoses foram visualizadas em grande quantidade no pericárdio e endocárdio (Fig.5), pleura parietal, mesentério, omento, serosa do rúmen (Fig.6), baço, pulmão, subcutâneo e musculatura intercostal e torácica lateral. Foi observada grande quantidade de folhas e poucos frutos de P. emarginatus no conteúdo do rúmen. 0 conteúdo fecal do reto estava extremamente seco, endurecido e sanguinolento.

Histologicamente, observou-se degeneração e necrose hepatocelular massiva moderada a acentuada, especialmente nas zonas periportal e intermediária, hiperplasia biliar multifocal moderada e bilestase multifocal leve (Fig.7). Nas áreas menos afetadas, notava-se degeneração microvacuolar difusa moderada a acentuada. Os rins apresentaram degeneração microvacuolar multifocal moderada nos túbulos contorcidos proximais e distais. No interstício do pulmão, observou-se áreas focalmente extensas de hemorragia, edema e infiltrado de neutrófilos. Não foram observadas alterações no encéfalo.

Foi realizado tratamento em todos os bovinos afetados com fluidoterapia (soro glicosado), antitóxico, vitamina K e óleo de soja por via oral. A maioria dos bovinos recuperou,

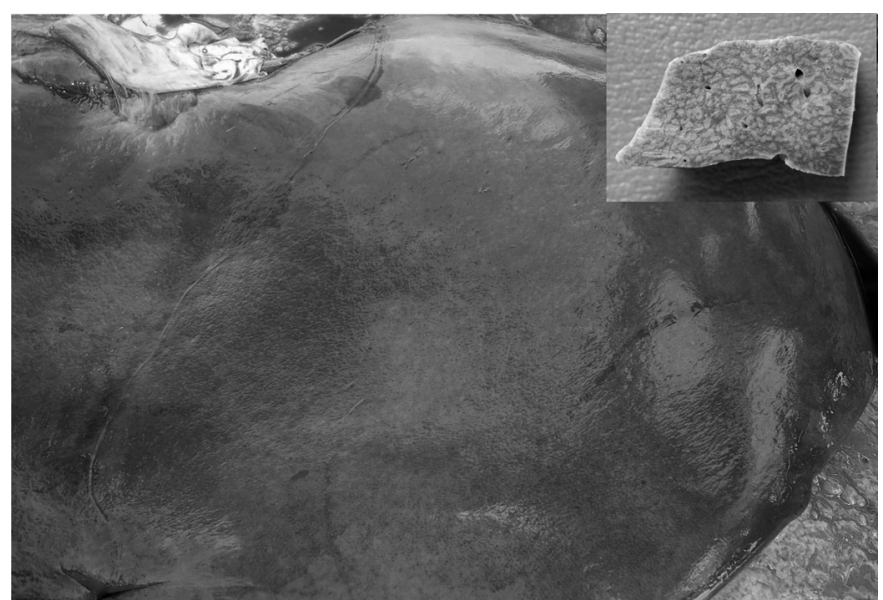

Fig.4. Fígado com áreas irregulares, esbranquiçadas ou amareladas, friáveis, multifocais a coalescentes, na intoxicação por Pterodon emarginatus (Bovino1). No detalhe, nota-se fragmento de fígado fixado evidenciando aumento acentuado do padrão lobular.

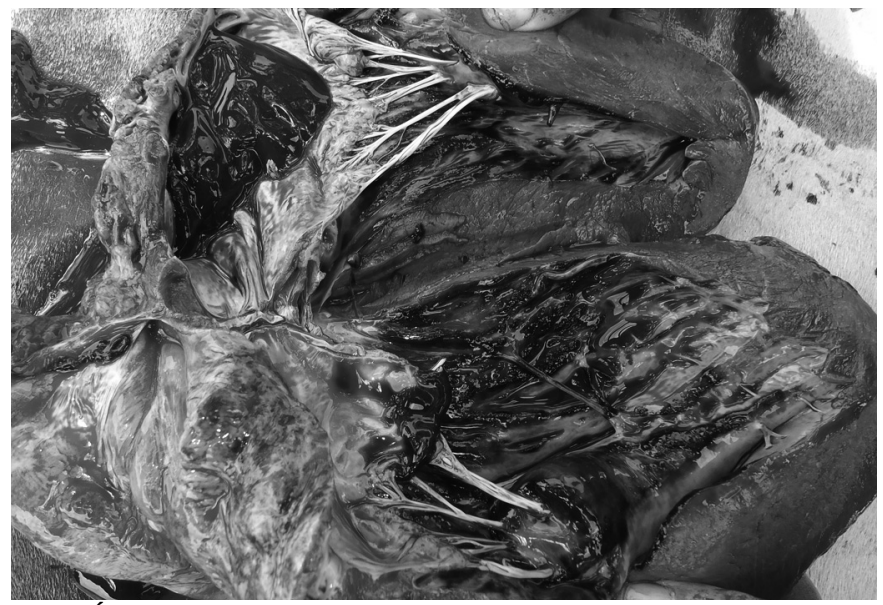

Fig.5. Áreas multifocais de hemorragia no endocárdio ventricular, na intoxicação por Pterodon emarginatus (Bovino 2).

mas após dez dias do início dos sinais clínicos, ainda haviam nove animais doentes muito debilitados.

\section{DISCUSSÃO}

As alterações macro e microscópicas, especialmente as hepáticas, observadas nos dois bovinos necropsiados, associadas à presença da planta e indícios de consumo de Pterodon emarginatus da árvore caída no pasto, ao aumento

\section{Quadro 1. Valores de atividades de AST, ALT e GGT e teores de bilirrubina total, direta e indireta em bovinos intoxicados espontaneamente por Pterodon emarginatus no Estado de Goiás}

\begin{tabular}{ccccccc}
\hline $\begin{array}{l}\text { Valores de } \\
\text { referência* }\end{array}$ & AST (UI/L) & ALT (UI/L) & GGT (UI/L) & BT (mg/dL) & BD (mg/dL) & BI (mg/dL) \\
\hline Bovino 1 & $20-34$ & $14-38$ & $6,1-17,4$ & $0,01-0,47$ & $0,04-0,44$ & 0,03 \\
Bovino 2 & 161 & 76 & 247 & 7,89 & 3,53 & 4,36 \\
Bovino 3 & 165 & 71 & 326 & 10,92 & 2,81 & 8,11 \\
Bovino 4 & 316 & 116 & 229 & 8,35 & 2,76 & 5,59 \\
Bovino 5 & 480 & 82 & 186 & 3,27 & 1,74 & 1,53 \\
${ }^{*}$ Kaneko et al. (2008). & & & & & & \\
\end{tabular}




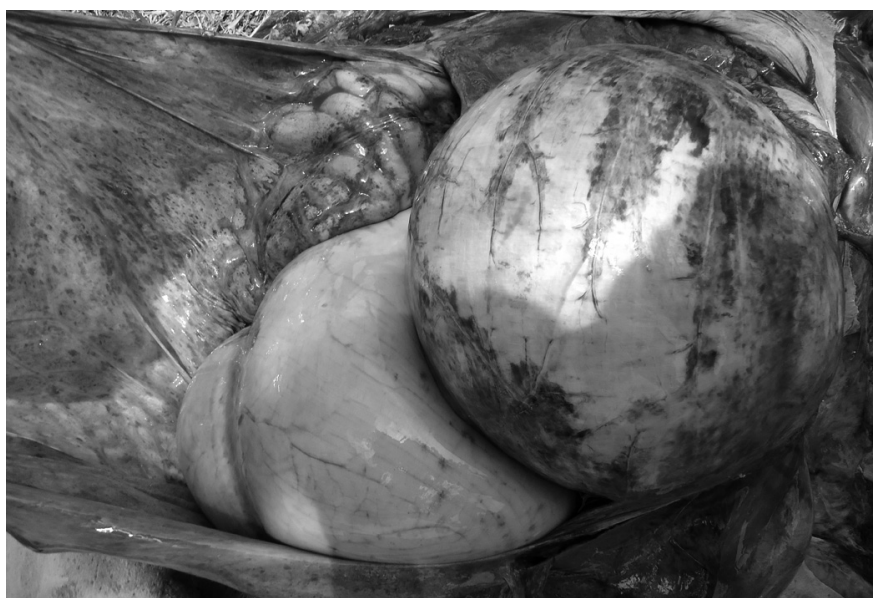

Fig.6. Hemorragias irregulares no omento, mesentério e serosa do rúmen, na intoxicação de bovino por Pterodon emarginatus (Bovino1).

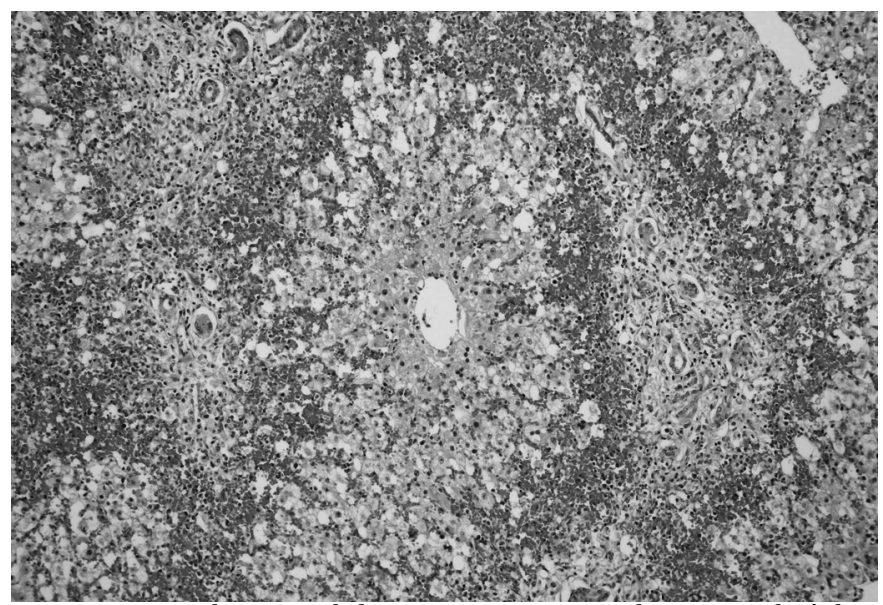

Fig.7. Necrose hepatocelular massiva acentuada associada à hemorragia e hiperplasia biliar, na intoxicação de bovino por Pterodon emarginatus. HE, obj.20x.

da atividade sérica e dos teores de enzimas hepáticas (AST, ALT, GGT e bilirrubina) e a eliminação de outros diagnósticos diferenciais que cursam com necrose hepática, conduziram ao diagnóstico de intoxicação por P. emarginatus.

Um surto de intoxicação por $P$. emarginatus em vacas foi recentemente observado no Estado de Mato Grosso (Arruda et al. 2008). Esse surto foi observado no mês de outubro, após a derrubada de duas árvores de $P$. emarginatus para aproveitamento de madeira; a morbidade e a mortalidade foram de $5 \%$. No presente trabalho, o surto de intoxicação ocorreu na mesma época do ano, mas o fator que contribuiu para o acesso dos bovinos as folhas da árvore foi a queda da planta após fortes ventos e tempestades. 0 índice de mortalidade do presente estudo foi semelhante ao observado em Mato Grosso (Arruda et al. 2008), entretanto a morbidade foi muito maior no surto verificado em Goiás (100\%).

Os sinais clínicos observados pelos bovinos intoxicados do presente estudo foram principalmente de natureza neurológica e digestiva e foram muito semelhantes aos notados no surto de intoxicação por P. emarginatus em Mato Grosso (Arruda et al. 2008) e nas intoxicações por plantas e insetos
(Perreyia flavipes) que determinam necrose hepática aguda no Brasil (Tokarnia et al. 2000, Riet-Correa et al. 2009). Na presente investigação, a acentuada elevação das atividades séricas das enzimas hepáticas em cinco bovinos intoxicados foi compatível com a grave injúria ao fígado detectada nos exames macro e microscópico.

Duas alterações comuns nos dois bovinos necropsiados foram necrose hepática e hemorragias em vários órgãos e tecidos. Achados patológicos muito semelhantes foram detectados no surto em Mato Grosso (Arruda et al. 2008) e em outras intoxicações por plantas, diagnosticadas no Brasil, que afetam o fígado (Tokarnia et al. 2000, Riet-Correa et al. 2009).

Diagnóstico diferencial foi realizado especialmente com as intoxicações pelas plantas Cestrum parqui (Riet-Correa et al. 1986), C. corymbosum (Gava et al. 1991), C. intermedium (Gava et al. 1996), C. laevigatum (Döbereiner et al. 1969), Xanthium cavanillesii (Driemeier et al. 1999), Vernonia mollissima (Döbereiner et al. 1976), V. rubricaulis (Tokarnia \& Döbereiner et al. 1982), Sessea brasiliensis (Canella et al. 1968), Trema micrantha (Traverso et al. 2004), Dodonea viscosa (Colodel et al. 2003) e pelas larvas de P. flavipes (Soares et al. 2008). Das plantas mencionadas acima, apenas $C$. laevigatum pode ser encontrada em quantidades suficientes para causar intoxicação em herbívoros no Estado de Goiás (Tokarnia et al. 2000).

Embora numerosos trabalhos fitoquímicos tenham identificados várias moléculas nas sementes de P. emarginatus, incluindo diterpenóides, isoflavonas e alcalóides (Dutra et al. 2008), em apenas uma investigação recente foram detectados os compostos químicos presentes nas folhas da planta. Essa análise identificou nove hidrocarbonetos sesquiterpênicos, sendo os principais o $\gamma$-muuroleno e o biciclogermacreno, e os esteróides estigmasterol e $\beta$-sitosterol (Santos et al. 2010). É preciso determinar em investigações futuras se esses compostos, recentemente identificados, são responsáveis pelas graves lesões, principalmente hepáticas, que ocorrem nos bovinos intoxicados por P. emarginatus. 0 princípio tóxico presente nas plantas que causam necrose hepática em herbívoros no Brasil, geralmente, é desconhecido, embora alcalóides, saponinas e um glicosídeo tenham sido encontrados em C. parqui (López et al. 1984, Tokarnia et al. 2000) e saponinas e cestrumida estejam presentes em C. laevigatum (Tokarnia et al. 2000).

Para o conhecimento dos autores, essa parece ser a primeira descrição da intoxicação espontânea por Pterodon emarginatus em bovinos no Estado de Goiás. Medidas profiláticas como dificultar o acesso de bovinos aos galhos das árvores podados ou caídos ao solo após tempestades, principalmente na seca e no início da estação chuvosa onde há escassez de forragem de boa qualidade, são úteis para prevenir a intoxicação.

Agradecimentos.- À Profa. Luzia Francisca de Souza do Herbário Jataiense (CAJ-UFG) pela identificação botânica da planta e ao Sr. Edismauro Garcia Freitas pela realização das análises de bioquímica sérica.

\section{REFERÊNCIAS}

Arruda L.P., Ferreira E.V., Boabaid F.M., Rocha P.R.D., Cruz R.A.S., Ubiali D.G., Mendonça F.S., Gasparetto N.D., Nespoli J.E., Souza F. \& Colodel E.M. 
2008. Intoxicação por Pterodon emarginatus (Fabaceae) em bovinos. Anais Encontro Nacional de Diagnóstico Veterinário, Campo Grande, MS, p.165-166. (Resumo)

Canella C.F.C., Tokarnia C.H. \& Döbereiner J. 1968. Intoxicação por Sessea brasiliensis Toledo em bovinos. Pesq. Agropec. Bras. 3:333-340.

Coelho M.G., Sabino K.C. \& Dalmau S.R. 2004. Immunomodulatory effects of sucupira (Pterodon pubescens) seed infusion on collagen-induced arthritis. Clin. Exp. Rheumatol. 22:213-218.

Coelho L.P., Reis P.A., Castro F.L., Gayer C.R.M., Lopes C.S., Silva M.C.C., Sabino K.C.C., Todeschini A.R. \& Coelho M.G.P. 2005. Anti-nociceptive properties of ethanolic extract and fractions of Pterodon pubescens Benth. seeds. J. Ethnopharmacol. 98:109-116.

Colodel E.M., Traverso S.D., Seitz A.L., Oliveira F.N., Driemeier D. \& Gava A. 2003. Spontaneous poisoning by Dodonea viscosa (Sapindaceae) in cattle. Vet. Hum. Toxicol. 45:147-148.

Döbereiner J., Tokarnia C.H. \& Canella C.F.C. 1969. Intoxicação por Cestrum laevigatum Schlecht, a causa de mortandades em bovinos no Estado do Rio de Janeiro. Pesq. Agropec. Bras. 4:165-193.

Döbereiner J., Tokarnia C.H. \& Purisco E. 1976. Vernonia molissima, planta tóxica responsável por mortandades de bovinos no sul de Mato Grosso. Pesq. Agropec. Bras. 11:49-58.

Driemeier D., Irigoyen L.F., Loretti A.P., Colodel E.M. \& Barros C.S.L. 1999. Intoxicação espontânea pelos frutos de Xanthium cavanillesii (Asteraceae) em bovinos no Rio Grande do Sul. Pesq. Vet. Bras. 19:12-18.

Gava A., Stolf L., Pilati C., Neves D.S. \& Viganó L. 1991. Intoxicação por Cestrum corymbosum var. hirsutum (Solanaceae) em bovinos no Estado de Santa Catarina. Pesq. Vet. Bras. 11:71-74.

Gava A., Stolf L., Varaschin M.S., Neves D.S., Tigre A.P. \& Lessmann F. 1996. Intoxicação por Cestrum intermedium (Solanaceae) em bovinos. Pesq. Vet. Bras. 16:117-120.

López T., Keeler R.F., Sharma R.P. \& Schupe J.L. 1984. Algunas sustancias quimicas vinculadas com La toxicidad de Cestrum parqui L'Héritier. Vet. Argent. 1:966-967.

Dutra R.C., Leite M.N. \& Barbosa N.R. 2008. Quantification of phenolic con- tituents and antioxidant activity of Pterodon emarginatus Vogel seeds. Int. J. Mol. Sci. 9:606-614.

Kaneko J.J., Harvey J.W. \& Bruss M.L. 2008. Clinical Biochemistry of Domestic Animals. ${ }^{\text {th }}$ ed. Academic Press, San Diego. 932p.

Lorenzi H. 2008. Árvores Brasileiras: manual de identificação e cultivo de plantas arbóreas nativas do Brasil. Vol.1. 5a ed. Instituto Plantarum, Nova Odessa. 384p.

Mahajan J.R. \& Monteiro M.B. 1970. New diterpenoids from Pterodon emarginatus Vog. Anais Acad. Bras. Ciênc. 42:103-107.

Mors W.B., Santos M.F. \& Monteiro H.B. 1967. Chemoprophyloactic agent in schistosomiasis: 14,15-epoxygeranylgeraniol. Science 157:950951.

Oliveira D.M.T. \& Paiva E.A.S. 2005. Anatomy and ontogeny of Pterodon emarginatus (Fabaceae: Faboideae) seed. Braz. J. Biol. 65:483-494.

Riet-Correa F., Schild A.L. \& Méndez M.C. 1986. Intoxicação por Cestrum parqui (Solanaceae) em bovinos no Rio Grande do Sul. Pesq. Vet. Bras. 6:111-115.

Riet-Correa F., Medeiros R.M.T., Pfister J., Schild A.L. \& Dantas A.F.M. 2009. Poisoning by plants, mycotoxins and related substances in Brazilian livestock. Sociedade Vicente Pallotti, Patos. 246p.

Santos A.P., Zatta D.T., Moraes W.F., Bara M.T.F., Ferri P.H., Silva M.R.R. \& Paula J.R. 2010. Composição química, atividade antimicrobiana do óleo essencial e ocorrência de esteróides na folha de Pterodon emarginatus Vogel, Fabaceae. Revta Bras. Farmacogn. 20:891-896.

Soares M.P., Quevedo P.S. \& Schild A.L. 2008. Intoxicação por larvas de Perreyia flavipes em bovinos na região Sul do Rio Grande do Sul. Pesq. Vet. Bras. 28:169-173.

Tokarnia C.H. \& Döbereiner J. 1982. Intoxicação de bovinos por Vernonia rubricaulis (Compositae) em Mato Grosso. Pesq. Vet. Bras. 2:143-147.

Tokarnia C.H., Döbereiner J. \& Peixoto P.V. 2000. Plantas Tóxicas do Brasil. Editora Helianthus, Rio de Janeiro. 310p.

Traverso S.D., Côrrea A.M.R., Schmitz M., Colodel E.M. \& Driemeier D. 2004. Intoxicação experimental por Trema micrantha (Ulmaceae) em bovinos. Pesq. Vet. Bras. 24:211-216. 